Tạp chí Khoa học và Công nghệ biển T10 (2010). Số 4. Tr 51 - 66

\title{
ĐộNG VẬT KHÔNG XƯƠNG SỐNG KÍCH THƯớC LỚN TRÊN RẠN SAN HÔ VÙNG BIỂN VEN BỜ TỈNH PHÚ YÊN
}

\author{
HOÀNG XUÂN BỀN, HỨA THÁI TUYẾN
}

Viện Hải dương học

\begin{abstract}
Tóm tắt: Kết quả nghiên cứu đã xác định được 97 loài thuộc 40 họ, trong đó ngành thân mềm (Mollusca) có số luợng nhiều nhất với 75 loài thuộc 16 họ, lớp Cầu gai (Echinoidea) 8 loài thuộc 4 họ, lớp Hải sâm 8 loài 3 họ. Thành phần loài ở đới sâu đều nhiều hon so với đới nông. Các điểm có thành phần loài cao là hòn Yến, bãi Nam có cùng 40 loài, bãi Nồm 35 loài và hòn Dưa 34 loài. Chi số đa dạng cao nhất thuộc về hòn Yến, bãi Gò và thấp nhất thuộc về vũng La, bãi Phú. Mật độ trung bình của các nhóm Động vật không xuơng sống (ĐVCXS) kích thuớc lớn đạt giá trị 20,9 con/100 m², mật độ này cao nhất tại hòn Nua đạt giá trị $42 \mathrm{con} / 100 \mathrm{~m}^{2}$ và thấp nhất tại bãi Phú chỉ đạt 4,5 con/100 $\mathrm{m}^{2}$. Hầu hết các điểm nghiên cứu mạt độ ở đới sâu đều cao hơn đới cạn, trung bình tuơng ứng là 25,4 con/100 $\mathrm{m}^{2}$ và $15,2 \mathrm{con} / 100 \mathrm{~m}^{2}$. Mật độ trung bình ĐVKXS trên rạn san hô tập trung vào nhóm Da gai 19,1 con/100 $\mathrm{m}^{2}$ chiếm tỉ lệ $91,1 \%$. Kết quả cũng ghi nhận tại 3 dạng quần xã sinh vật đặc trung cho ĐVKXS trên rạn san hô vùng biển ven bờ tỉnh Phú Yên, Quần xã A: ghi nhận tại ba điểm khảo sát là vũng La, bãi Phú và hòn Chùa. Quần xã B: ghi nhận ở các điểm khảo sát bãi Nồm, vịnh Hoà, bãi Nam, bãi Gò và hòn Nua và Quần xã C ghi nhận tại hai điểm khảo sát là hòn Yến và Tù Nham.
\end{abstract}

\section{MỞ ĐẦU}

Phú Yên là tỉnh duyên hải Nam Trung bộ, có đường bờ biển dài gần $200 \mathrm{~km}$. Vùng ven bờ tồn tại nhiều vũng, vịnh, đầm đặc trưng bởi các hệ sinh thái như rừng ngập mặn, thảm cỏ biển, rạn san hô với nhiều nguồn lợi thuỷ hải sản quan trọng góp phần phát triển kinh tế xã hội của tỉnh và duy trì đời sống của cộng đồng dân cư ven biển. Bài báo này là một phần trong các nội dung nghiên cứu đầu tiên về hệ sinh thái rạn san hô vùng biển ven bờ Phú Yên trình bày về đặc điểm đa dạng, mật độ, phân bố của Động vật không xương sống kích thước lớn tập trung vào hai nhóm chính là Thân mềm và Da gai (Hải sâm, Sao Biển và Cầu gai) với mục đích cung cấp các dữ liệu đầu tiên và mới nhất về đa dạng sinh học của ĐVKXS trên rạn san hô vùng biển ven bờ Phú Yên góp phần nghiên cứu đa dạng sinh học hệ sinh thái rạn san hô từ đó có kế hoạch quản lý và bảo tồn các hệ sinh thái quan trọng cho vùng biển đầy tiềm năng này. 


\section{TÀI LIỆU VÀ PHƯƠNG PHÁP NGHIÊN CÚU}

\section{Thời gian và địa điểm khảo sát:}

Nghiên cứu về quần xã động vật không xương sống kích thước lớn trên rạn san hô được tiến hành từ ngày 16 - 26 tháng 4 năm 2009, bao gồm 11 điểm khảo sát dọc theo vùng biển ven bờ tỉnh Phú Yên (theo kí hiệu lần lượt từ Bắc vào Nam tại bảng 1 và hình 1). Trong đó, khu vực đầm Cù Mông có hai điểm là Bãi Nồm (phía Bắc vịnh) và vịnh Hoà (phía Nam vịnh), khu vực vịnh Xuân Đài có 3 điểm khảo sát là Từ Nham, Vũng La và hòn Yến, khu vực An Hải có 2 điểm tại đảo Cù Lao Mái Nhà là bãi Phú và bãi Nam, khu vực An Chấn có 3 điểm là hòn Chùa, hòn Dứa và bãi Gò, một điểm còn lại tại hòn Nưa ở Vũng Rô. Cơ sở khoa học để chọn các điểm này dựa trên kết quả đánh giá nhanh rạn san hô trên diện rộng bằng phương pháp Manta tow, và điều tra tham vấn cộng đồng. Từ đó, chọn các điểm nghiên cứu mang tính chất đặc trưng cho hệ sinh thái rạn san hô vùng biển ven bờ Phú Yên.

Bảng 1: Vị trí các điểm khảo sát rạn san hô ở vùng biển ven bờ tỉnh Phú Yên

\begin{tabular}{|c|c|c|c|c|}
\hline Kí hiệu & Địa điểm & Khu vụ̣c & Vĩ độ & Kinh độ \\
\hline 1 & Bãi Nồm & Đầm Cù Mông & $13^{0} 56.756$ & $109^{0} 29.436$ \\
\hline 2 & Vịnh Hoà & Đầm Cù Mông & $13^{0} 50.739$ & $109^{0} 29.956$ \\
\hline 3 & Từ Nham & Vịnh Xuân Đài & $13^{0} 46.191$ & $109^{0} 32.577$ \\
\hline 4 & Vũng La & Vịnh Xuân Đài & $13^{0} 30.280$ & $109^{0} 41.284$ \\
\hline 5 & Hòn Yến & Vịnh Xuân Đài & $13^{0} 41.273$ & $109^{0} 30.182$ \\
\hline 6 & Bãi Phú & Cù Lao Mái Nhà & $13^{0} 27.870$ & $109^{0} 34.237$ \\
\hline 7 & Bãi Nam & Cù Lao Mái Nhà & $13^{0} 28.471$ & $109^{0} 32.723$ \\
\hline 8 & Hòn Chùa & An Chấn & $13^{0} 17.229$ & $109^{0} 31.301$ \\
\hline 9 & Hòn Dứa & An Chấn & $13^{0} 16.800$ & $109^{0} 31.928$ \\
\hline 10 & Bãi Gò & An Chấn & $13^{0} 18.375$ & $109^{0} 30.346$ \\
\hline 11 & Hòn Nưa & Vũng Rô & $12^{0} .49 .648$ & $109^{0} 39.094$ \\
\hline
\end{tabular}




\section{Phương pháp nghiên cứu}

Tại mỗi vị trí khảo sát, hai mặt cắt ngang mỗi mặt cắt dài $100 \mathrm{~m}$ (chia làm 4 đoạn, mỗi đoạn dài $20 \mathrm{~m}$ ) được đặt tại các độ sâu khác nhau, mặt cắt cạn đặt trên mặt bằng rạn khoảng $2-4 \mathrm{~m}$ và mặt cắt sâu trên sườn dốc khoảng từ $4-8 \mathrm{~m}$ tùy thuộc vào cấu trúc của mỗi rạn. Việc khảo sát tiến hành theo 4 đoạn của mỗi dây mặt cắt (English et al, 1997). Để nghiên cứu ĐVKXS chúng tôi bơi chậm để quan sát và ghi nhận các nhóm sinh vật trên mặt cắt, thời gian để hoàn thành một mặt cắt khoảng 40 phút và ghi nhận các thông tin như sau:

- Xác định mật độ: tất cả các ĐVKXS thuộc hai nhóm Thân mềm và Da gai (Hải sâm, Sao biển và Cầu gai) bắt gặp tại các điểm khảo sát đều được ghi nhận theo từng đoạn dài $20 \mathrm{~m}$ và rộng $5 \mathrm{~m}$ của mặt cắt và diện tích xác định cho mỗi đoạn là 100 m².

- Xác định thành phần loài: ngoài việc ghi nhận theo mặt cắt đặt trên các đới cạn và sâu của từng điểm rạn khảo sát, chúng tôi còn lặn các khu vực xung quanh để ghi chép, thu mẫu các loài chưa được ghi nhận trên mặt cắt hoặc chưa thể định loại dưới nước để bổ sung vào danh mục thành phần loài của từng điểm khảo sát. Phân loại dựa theo các tài liệu phân loại đến loài và giống theo Allen \& Steen, 1994; Colin \& Arneson, 1995; Goslinger et al., 1996.

- Nghiên cứu cấu trúc quần xã: để nghiên cứu về cấu trúc quần xã của các nhóm sinh động vật không xương sống kích thước lớn trên rạn san hô. Dùng phương pháp đánh giá nhanh - REA (Rapid Ecological Assessment). Trên từng mặt cắt, mỗi chuyên gia lặn tiến hành bơi chậm theo đường "Zíc Zắc" với chiều rộng là $5 \mathrm{~m}$ dọc theo dây mặt cắt dài $50 \mathrm{~m}$ để ghi nhận sự phong phú theo từng loài hoặc giống của các nhóm sinh vật bắt gặp.

Tất cả các dữ liệu thu thập được xử lý và phân tích bằng Excel, đối với phân tích cấu trúc quần xã sử dụng phần mềm Primer 5.0 để phân tích (trong tính toán này $\mathrm{s}$ kí hiệu ở mặt bằng rạn và $\mathrm{d}$ kí hiệu ở sườn dốc rạn, các số 1 - 11 là kí hiệu của các vị trí nghiên cứu theo bảng 1 ở trên).

Nghiên cứu tính đa dạng của ĐVKSX, sử dụng các công thức:

Chỉ số đa dạng loài $\mathrm{H}^{\prime}=-\sum \mathrm{P}_{\mathrm{i}} \log _{2} \mathrm{P}_{\mathrm{i}}$

Mức độ giàu có thành phần loài

$$
\mathrm{d}:=(\mathrm{S}-1) / \log _{2}(\mathrm{~N})
$$

trong đó: $\quad \mathrm{P}_{\mathrm{i}}=\mathrm{N}_{\mathrm{i}} / \mathrm{N}$
$\mathrm{N}_{\mathrm{i}}$ : là số cá thể của loài thứ $\mathrm{i}$
$\mathrm{N}$ : tổng số cá thể
S: tổng số loài 


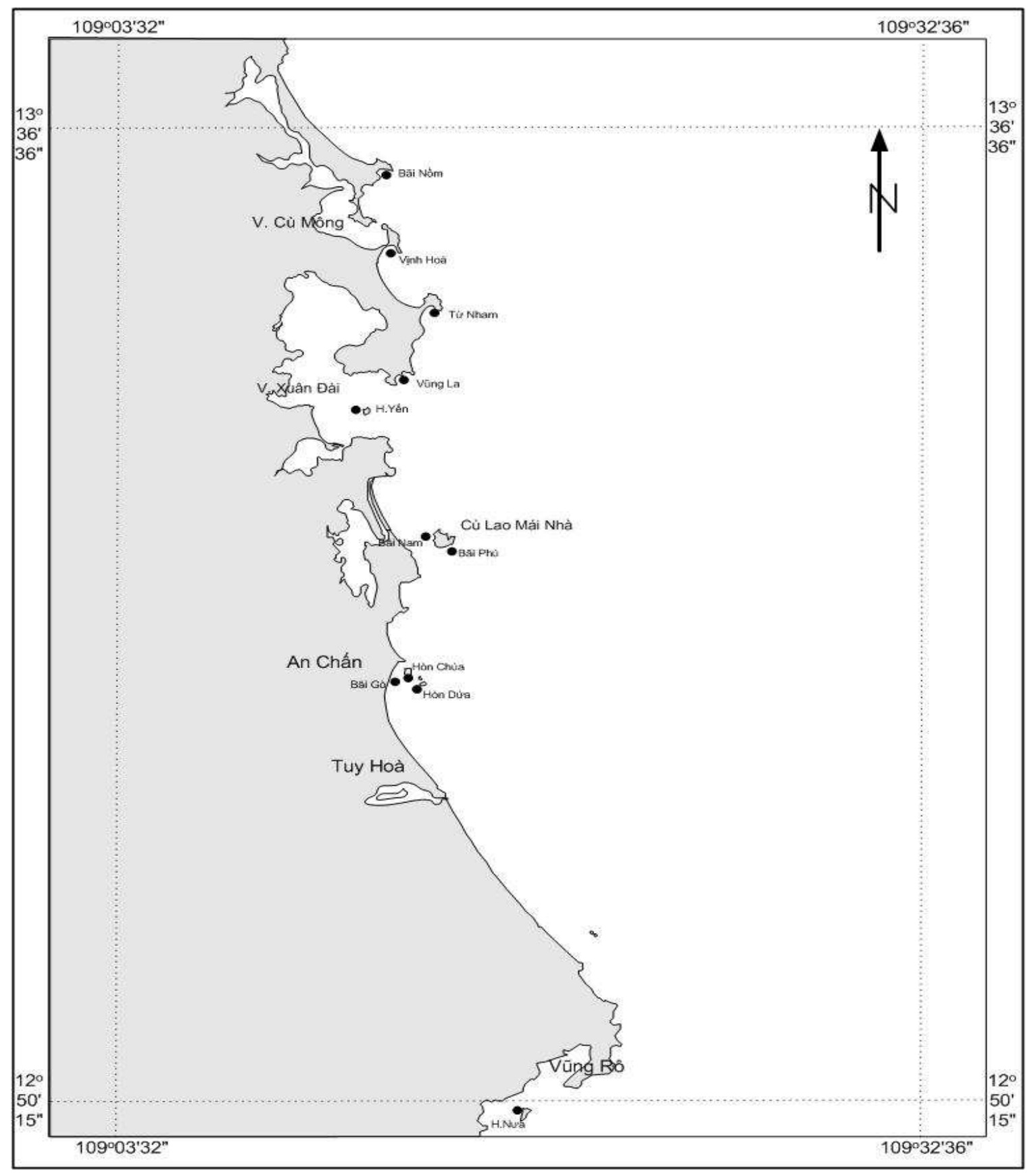

Hình 1: Sơ đồ $(\bullet)$ vị trí khảo sát ĐVKXS vùng biển ven bờ Phú Yên

\section{KÊT QUẢ NGHIÊN CÚU VÀ THẢO LUẬN}

\section{1. Đặc điểm đa dạng}

Kết quả nghiên cứu đã xác định được 97 loài thuộc 40 họ (Phụ lục 1). Trong đó 
nhóm Thân mềm có số lượng nhiều nhất với 75 loài thuộc 16 họ chiếm tỉ lệ $76,3 \%$ tổng số loài, tiếp đến là lớp Cầu gai ( 8 loài thuộc 4 họ) và Hải sâm ( 8 loài thuộc 3 họ) cùng chiếm tỉ lệ 7,9\% và thấp nhất là Sao biển (6 loài thuộc 4 họ chiếm tỉ lệ $6,2 \%)$. Nhìn chung, thành phần loài ở đới sâu đều nhiều hơn so với đới cạn, trung bình tại tất cả các điểm nghiên cứu đạt giá trị tương ứng là 73 và 87 loài. Kết quả cho thấy vũng La và hòn Yến (vịnh Xuân Đài) là nơi có thành phần loài nhiều nhất (tương ứng là 39 và 40 loài) tiếp đến là bãi Nam (Cù Lao Mái Nhà) có 40 loài, bãi Nồm có 35 loài và hòn Dứa ghi nhận 34 loài. Điểm khảo sát có thành phần loài ít nhất là bãi Phú (Cù Lao Mái Nhà) chỉ ghi nhận được 20 loài. Các điểm còn lại số lượng loài tương đối bằng nhau, dao động từ $27-31$ loài. Hai điểm khảo sát là hòn Yến và bãi Phú không ghi nhận loài Hải sâm nào (bảng 2).

Trong số 97 loài, có những loài khá hiếm gặp ở các điểm khảo sát như lớp Cầu gai có hai loài là Echinometra $s p$. và Prionocidaris sp. chỉ xuất hiện tại hai điểm khảo sát tương ứng là hòn Yến và bãi Gò, lớp Hải sâm có ba loài là Holothuria leucospilota, Bohadchia argus và Bohadchia graeffei chỉ gặp tại 3 điểm khảo sát lần lượt là bãi Nồm, hòn Dứa và hòn Nưa, lớp Sao biển có loài Fromia sp. ghi nhận tại hai điểm khảo sát là bãi Nam và bãi Gò. Nhóm Thân mềm cũng ghi nhận nhiều loài chỉ bắt gặp tại một điểm khảo sát nhu: Anadara antiquata, Cerithium citrinum, Haliotis ovina, Lambis crocata...

Bảng 2: Số lượng loài động vật không xương sống kích thước lớn trên rạn san hô tại các điểm khảo sát ở vùng biển ven bờ tỉnh Phú Yên

\begin{tabular}{|c|c|c|c|c|c|}
\hline \multirow[t]{2}{*}{ Vị trí khảo sát } & \multicolumn{4}{|c|}{ Nhóm sinh vật } & \multirow[t]{2}{*}{ Tổng cộng } \\
\hline & Cầu gai & Hải sâm & Sao biển & Thân mềm & \\
\hline Bãi Nồm & 5 & 6 & 4 & 20 & 35 \\
\hline Vịnh Hoà & 4 & 3 & 5 & 17 & 39 \\
\hline Từ Nham & 4 & 3 & 4 & 19 & 30 \\
\hline Vũng La & 4 & 1 & 3 & 31 & 39 \\
\hline Hòn Yến & 6 & 0 & 4 & 30 & 40 \\
\hline Bãi Phú & 3 & 0 & 2 & 15 & 20 \\
\hline Bãi Nam & 5 & 2 & 5 & 28 & 40 \\
\hline Hòn Chùa & 2 & 3 & 4 & 22 & 31 \\
\hline Hòn Dứa & 3 & 6 & 3 & 22 & 34 \\
\hline Bãi Gò & 3 & 1 & 4 & 24 & 32 \\
\hline Hòn Nưa & 5 & 3 & 4 & 15 & 27 \\
\hline Số loài & 8 & 8 & 6 & 75 & 97 \\
\hline
\end{tabular}


Kết quả tính toán cho thấy, những vị trí nghiên cứu nào có số lượng loài cao và tần số xuất hiện thấp thường có chỉ số $\mathrm{H}^{\prime}$ cao và ngược lại. Theo đó, chỉ số đa dạng cao nhất thuộc về hòn Yến $(4,267)$ tiếp đến là bãi Gò $(4,14)$ và thấp nhất thuộc về vũng $\mathrm{La}(2,206)$ và bãi Phú $(2,125)$ (bảng 3).

Bảng 3: Tính đa dạng của ĐVKXS tại các vị trí nghiên cứu vùng biển ven bờ tỉnh Phú Yên

\begin{tabular}{|c|c|c|c|c|}
\hline Địa điểm & Số lượng loài & Tần số xuất hiện & $\begin{array}{c}\text { Độ giàu có thành } \\
\text { phần loài }(\mathbf{d})\end{array}$ & $\begin{array}{c}\text { Chỉ số đa } \\
\text { dạng (H') }\end{array}$ \\
\hline Bãi Nồm & 33 & 384 & 5,378 & 3,482 \\
\hline Vịnh Hoà & 29 & 160 & 5,517 & 3,943 \\
\hline Từ Nham & 28 & 187 & 5,161 & 3,412 \\
\hline Vũng La & 37 & 534 & 5,732 & 2,206 \\
\hline Hòn Yến & 37 & 189 & 6,868 & 4,267 \\
\hline Bãi Phú & 20 & 282 & 3,368 & 2,125 \\
\hline Bãi Nam & 38 & 352 & 6,31 & 3,852 \\
\hline Hòn Chùa & 32 & 124 & 6,431 & 3,971 \\
\hline Bãi Gò & 32 & 133 & 6,339 & 4,14 \\
\hline Hòn Nưa & 24 & 371 & 3,888 & 3,386 \\
\hline
\end{tabular}

So sánh về thành phần loài động vật không xương sống kích thước lớn trên rạn san hô của khu vực nghiên cứu với một số khu vực khác như vùng biển Đà Nẵng, Cù Lao Chàm, Nha Trang, Phú Quốc cho thấy thành phần loài ghi nhận ở vùng biển ven bờ Phú Yên là khá phong phú so với các vùng nêu trên. Kết quả ở bảng 4 thể hiện số lượng loài ở Phú Yên đứng thứ $2 \mathrm{sau}$ vùng biển Cù Lao Chàm. Theo đó, nhóm Cầu gai có thành phần loài cao nhất, nhóm Hải sâm có thành phần loài đứng thứ 2 sau vùng biển Phú Quốc, nhóm Sao biển có số lượng loài đứng sau vùng biển Nha Trang và số loài thuộc nhóm Thân mềm đứng sau vùng biển Cù Lao Chàm. Tập hợp các nghiên cứu về thành phần loài ĐKXS trên rạn san hô ở vùng biển mang tính chất khơi như khu vực quần đảo Trường Sa của các tác giả Đào Tấn Hỗ (1991), Lăng Văn Kẻng (1996), Ninnette Lasola và Hoàng Xuân Bền (2008) cũng cho thấy Phú Yên là nơi có thành phần Thân mềm khá cao (bảng 4). 
Bảng 4: So sánh thành phần loài ĐVKXS trên rạn san hô ở vùng biển phía Nam Việt Nam (Nguyễn Văn Long vcs, 2006, 2007 và 2008. Ninnette Lasola và Hoàng Xuân Bền, 2008.

Đào Tấn Hỗ, 1991. Lăng Văn Kẻng, 1996)

\begin{tabular}{|c|c|c|c|c|c|c|}
\hline \multirow{2}{*}{$\begin{array}{c}\text { Nhóm } \\
\text { sinh vật }\end{array}$} & \multicolumn{7}{|c|}{ Khu vụ̣c nghiên cứu } \\
\cline { 2 - 7 } & Đà Nẵng & $\begin{array}{c}\text { Cù Lao } \\
\text { Chàm }\end{array}$ & $\begin{array}{c}\text { Nha } \\
\text { Trang }\end{array}$ & $\begin{array}{c}\text { Phú } \\
\text { Quốc }\end{array}$ & $\begin{array}{c}\text { Phú } \\
\text { Yên }\end{array}$ & $\begin{array}{c}\text { Trường } \\
\text { sa }\end{array}$ \\
\hline Thân mềm & 53 & 97 & 65 & 48 & 75 & 52 \\
\hline Sao biển & 6 & 4 & 9 & 2 & 6 & 18 \\
\hline Hải sâm & 7 & 4 & 7 & 17 & 8 & 11 \\
\hline Cầu gai & 4 & 6 & 6 & 4 & 8 & 7 \\
\hline Tổng cộng & 70 & 111 & 87 & 71 & 97 & 88 \\
\hline
\end{tabular}

\section{Mật độ và phân bố}

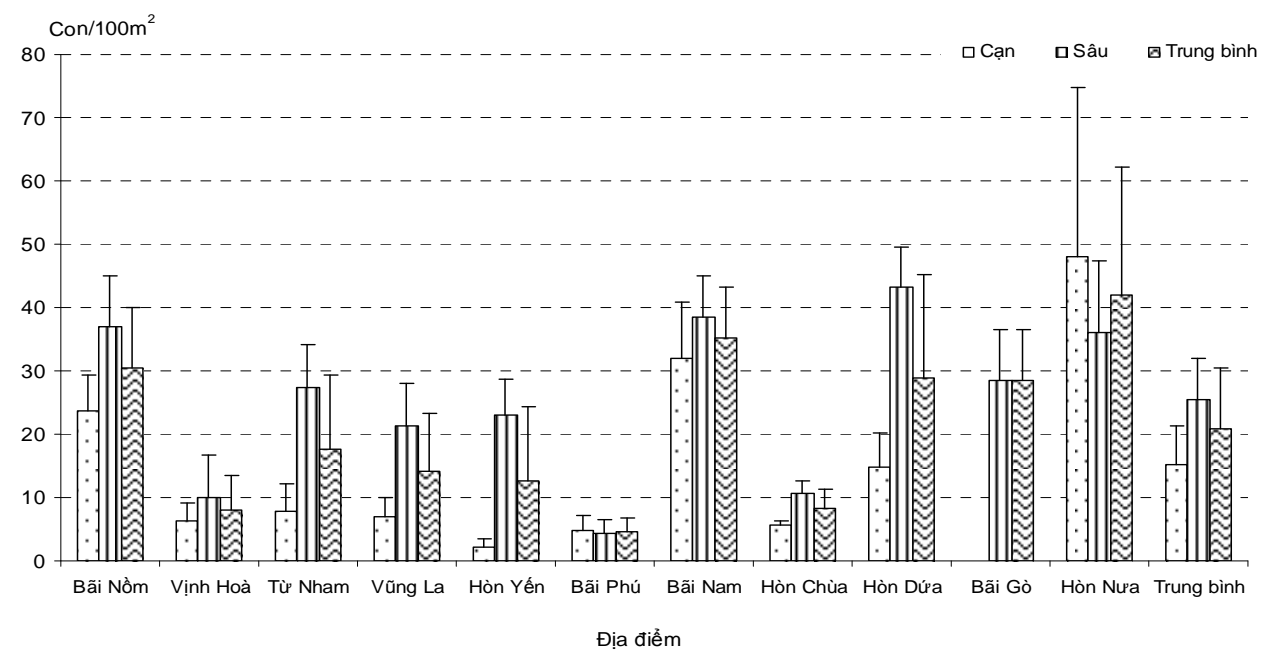

Hình 2: Mật độ $\left(c o n / 100 \mathrm{~m}^{2}\right)$ của ĐVKXS tại các điểm khảo sát vùng ven biển Phú Yên

Mật độ trung bình của các nhóm Động vật không xương sống kích thước lớn tại các điểm khảo sát đạt giá trị 20,9 con/100 m², mật độ này cao nhất tại hòn Nưa với mật độ 42 con/100 $\mathrm{m}^{2}$ và thấp nhất tại bãi Phú chỉ đạt $4,5 \mathrm{con} / 100 \mathrm{~m}^{2}$. Kết quả cũng cho thấy, hầu hết các điểm nghiên cứu mật độ động vật không xương sống kích thước lớn ở đới sâu đều cao hơn đới cạn với hai giá trị trung bình tương ứng là $25,4 \mathrm{con} / 100 \mathrm{~m}^{2}$ và $15,2 \mathrm{con} / 100 \mathrm{~m}^{2}$ (hình 2). Kết quả khảo sát cho thấy, mật độ trung bình của Động vật không xương sống kích 
thước lớn trên rạn san hô chủ yếu tập trung vào nhóm Da gai mà cụ thể là loài Cầu gai đen (Diadema setosum) đạt giá trị $19,1 \mathrm{con} / 100 \mathrm{~m}^{2}$ chiếm tỉ lệ $91,1 \%$ tổng số. Nhóm Thân mềm có mật độ khá thấp trung bình đạt 1,5 con/100 m² chiếm tỉ lệ $7,2 \%$ tổng số (hình 3).

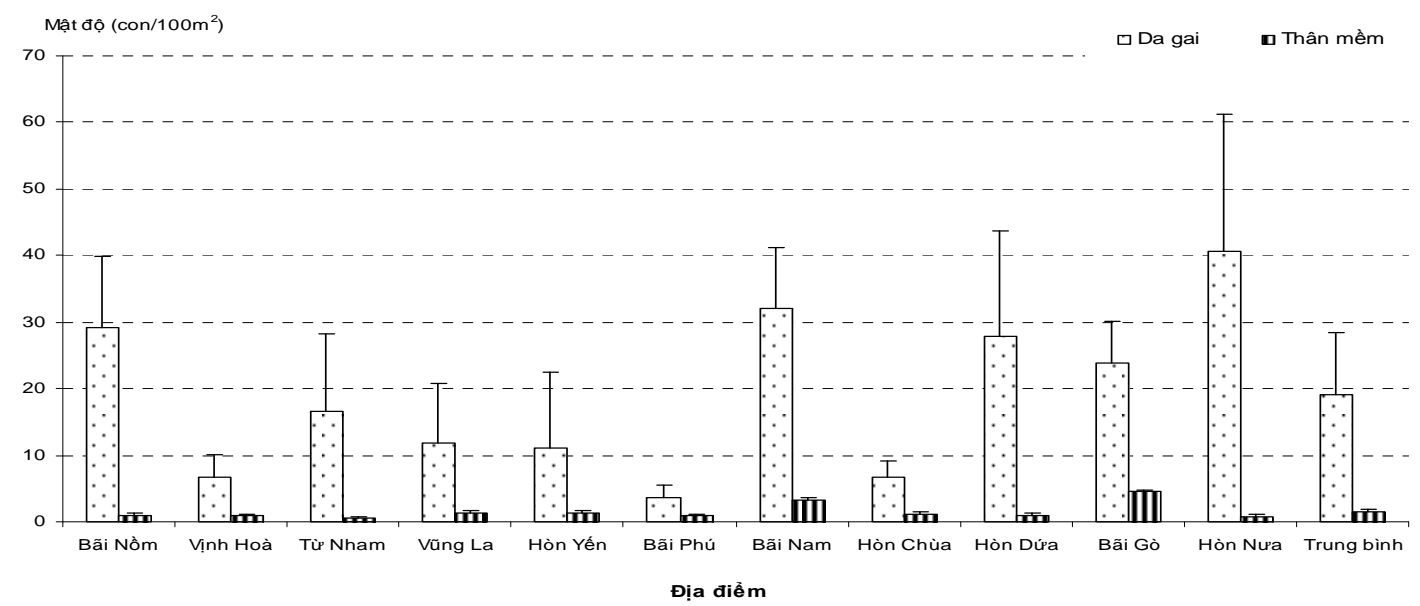

Hình 3: Mật độ $\left(c o n / 100 \mathrm{~m}^{2}\right)$ của ĐVKXS tại các điểm khảo sát vùng ven biển Phú Yên

So sánh về mật độ của nhóm Thân mềm và Da gai vùng biển ven bờ Phú Yên với các khu vực khác ở vùng biển Phía Nam Việt Nam cho thấy mật độ hai nhóm này ở vùng biển ven bờ Phú Yên ở mức độ trung bình. Theo đó, mật độ trung bình của nhóm Da gai ở Phú Yên thấp hơn ở vùng biển Phú Quốc và Cù Lao Chàm nhưng cao hơn Đà Nẵng, Nha Trang và Ninh Thuận. Mật độ trung bình của Thân mềm chỉ đứng thứ 2 sau vùng biển Đà Nẵng (bảng 5).

Bảng 5: So sánh mật độ (con/100 m²) giữa các vùng nghiên cứu phía Nam Việt Nam (Nguyễn Văn Long và cs, 2006, 2007 và 2008)

\begin{tabular}{|c|c|c|}
\hline \multirow{2}{*}{ Khu vực } & \multicolumn{2}{|c|}{ Nhóm sinh vật } \\
\cline { 2 - 3 } & Da gai & Thân Mềm \\
\hline Đà Nẵng & 9.3 & 67.3 \\
\hline Cù Lao Chàm & 29.5 & 0.8 \\
\hline Nha Trang & 17.5 & 0.39 \\
\hline Ninh Thuận & 1.6 & 0.6 \\
\hline Phú Quốc & 78.3 & 0.5 \\
\hline Phú Yên & 19.1 & 1.5 \\
\hline
\end{tabular}




\section{3. Đặc điểm cấu trúc quần xã}

Kết quả phân tích nhóm (Cluster analysis) về sự phong phú của quần xã ĐVKXS trên rạn san hô cho thấy sự khác biệt giữa các quần xã là khá lớn. Các phân tích thống kê (ANOSIM) cũng cho thấy sự khác nhau giữa các dạng quần xã sinh vật đáy là có ý nghĩa $(\mathrm{P}<0,05)$. Điều này cho thấy có sự khác biệt về thành phần loài cũng như mức độ ưu thế của một số loài đại diện trong quần xã sinh vật đáy giữa các điểm khảo sát. Phân tích chi tiết về thành phần của quần xã sinh vật đáy cho thấy, ở đây tồn tại 3 dạng quần xã đặc trưng cho ĐVKXS trên rạn san hô vùng biển ven bờ tỉnh Phú Yên, sự phân bố của các quần xã này có thể như sau (hình 4).

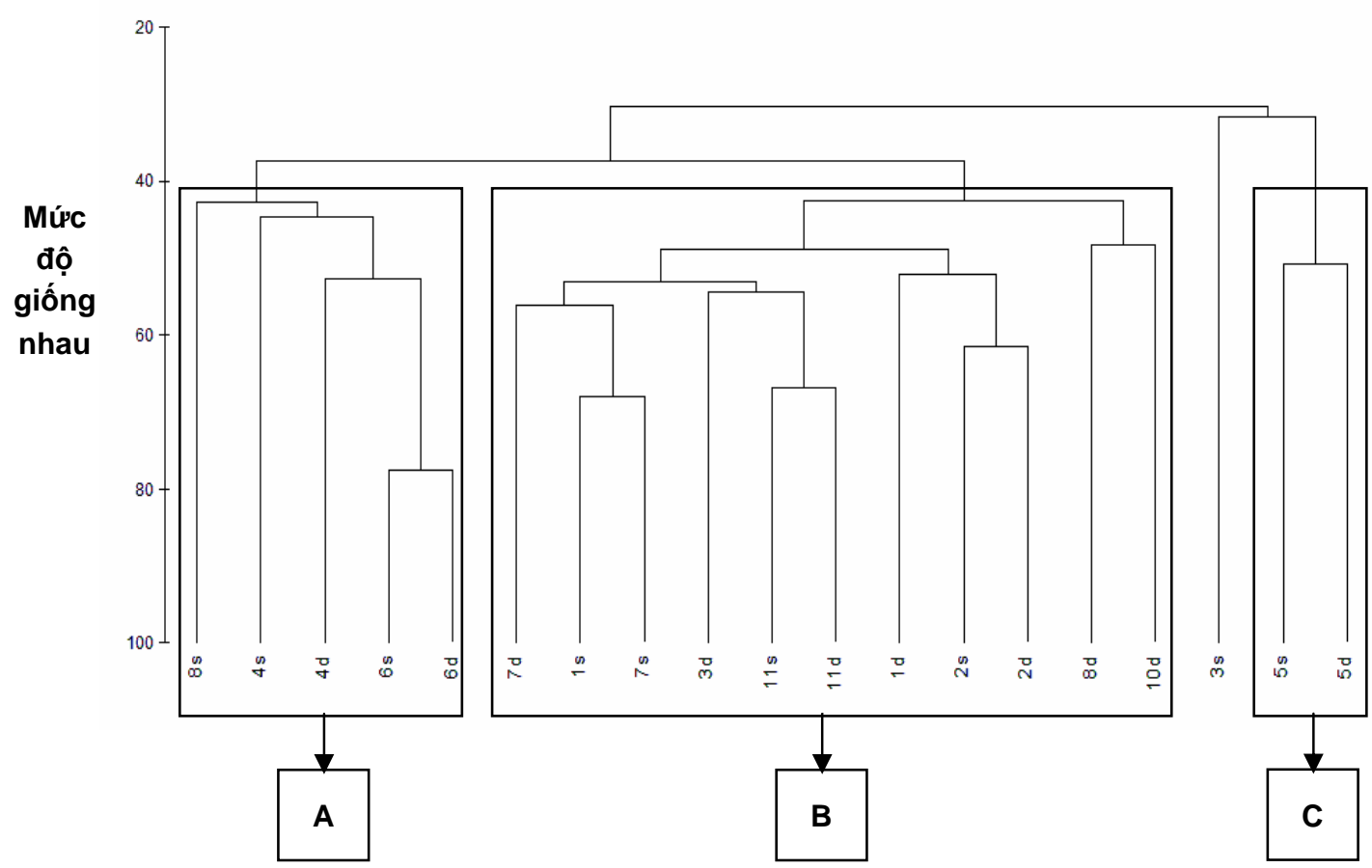

Hình 4: Phân tích nhóm (Cluster analysis) các dạng quần xã ĐVKXS trên rạn san hô vùng biển ven bờ Phú Yên

Quần xã A: ghi nhận tại ba điểm khảo sát là vũng La, bãi Phú và hòn Chùa, trong đó hòn Chùa ghi nhận tại mặt cắt cạn. Kiểu quần xã này đặc trưng bởi các loài thuộc nhóm Thân mềm là Drupella conus, Coraliophilla neritoidea và Trochus maculates.

Quần xã $B$ : đây là dạng quần xã ghi nhận ở rất nhiều các điểm khảo sát gồm bãi Nồm, vịnh Hoà, Từ Nham, bãi Nam, hòn Chùa, bãi Gò và hòn Nưa, trong đó Từ Nham và hòn Chùa chỉ ghi nhận cấu trúc quần xã tại đới sâu của rạn san hô. Kiểu cấu trúc quần xã này đặc trưng bởi các loài Echinothrix calamaris, Linckia laevigata, Diadema setosum, Diadema savignyi, Acanthaster planci, Culcita novaguineae, Synapta maculata, 
Tripnsueste gratilla, Pedum spondyloideum, Echinaster luzonicus và Chicoreus torrefactus.

Quần xã $C$ : dạng quần xã này ghi nhận tại hai điểm khảo sát là òn Yến và đới cạn của Từ Nham. Kiểu cấu trúc quần xã này đặc trưng bởi các loài Vasum turbinellus, Tectus pyramis, Mancinella mancinella, Conus miles, Malleus albus và Spondylus ducalis.

\section{KẾT LUẬN}

1. Xác định được 97 loài thuộc 40 họ, trong đó ngành Thân Mềm (Mollusca) có số lượng lớn nhất với 75 loài thuộc 16 họ, lớp Cầu gai (Echinoidea) 8 loài thuộc 4 họ, lớp Hải sâm (Holothuroidea) 8 loài thuộc 3 họ. Thành phần loài ở đới sâu đều cao hơn so với đới nông. Các điểm có thành phần loài cao là Vũng La- 39 loài và hòn Yến - 40 loài, Bãi Nam - 40 loài, Bãi Nồm - 35 loài và hòn Dứa - 34 loài. Chỉ số đa dạng cao nhất ở hòn Yến, bãi Gò và thấp nhất ở vũng La và bãi Phú.

2. Mật độ trung bình của các nhóm Động vật không xương sống kích thước lớn đạt giá trị 20.9 con/100 m², mật độ này cao nhất tại hòn Nưa đạt giá trị $42 \mathrm{con} / 100 \mathrm{~m}^{2}$ và thấp nhất tại bãi Phú chỉ đạt $4.5 \mathrm{con} / 100 \mathrm{~m}^{2}$. Hầu hết các điểm nghiên cứu mật độ ở đới sâu đều cao hơn đới cạn, trung bình tương ứng là $25.4 \mathrm{con} / 100 \mathrm{~m}^{2}$ và $15.2 \mathrm{con} / 100 \mathrm{~m}^{2}$. Mật độ trung bình ĐVKXS trên rạn san hô tập trung vào nhóm Da gai 19.1 con/100 m² chiếm tỉ lệ $91.1 \%$.

3. Các phân tích thống kê (ANOSIM) cho thấy ở đây tồn tại 3 dạng quần xã đặc trưng cho ĐVKXS trên rạn san hô vùng biển ven bờ tỉnh Phú Yên, Quần xã A: ghi nhận tại ba điểm khảo sát là vũng La, bãi Phú và hòn Chùa. Quần xã $B$ : ghi nhận ở các điểm

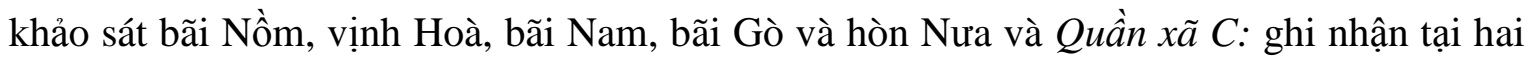
điểm khảo sát là hòn Yến và Từ Nham.

Lời cám ơn: các tác giả xin chân thành cảm ơn Ban quản lý chương trình SEMLA Phú Yên, Viện Hải Dương Học, Phòng Nguồn lợi Thuỷ sinh vật, PGS.TS. Võ Sĩ Tuấn (chủ trì dự án) đã tạo điều kiện cho chúng tôi được tham gia các chuyến khảo sát và sử dụng số liệu trong bài báo này.

\section{TÀI LIỆU THAM KHẢO}

1. Allen G.R., and Steene R., 1994. Indo-Pacific Coral Reef Field Guide. Tropical Reef Research, 378pp.

2. Colin P.L. and Arneson C., 1995. Tropical Pacific Invertebrates. Coral Reef Press, California, USA, 296pp. 
3. Conand C., 1989. The Fishery resources of Pacific Island countries. Part II. Holothuriana. FAO fisheries technical papers, No. 272.2. Rome, FAO, 143pp.

4. Đào Tấn Hỗ, 1991. Sơ bộ nghiên cứu Động vật Da gai (Echinodermata) ở Quần đảo Trường Sa. Phụ trương về một số kết quả nghiên cứu, Tạp Chí Sinh Học. Viện Khoa Học Việt Nam. Trang 44-47.

5. English S., C. Wilkinson and V. Baker, 1997. Survey manual for tropical marine resources. Australian Institute of Marine Science. Townsville, 390 pp.

6. Goslinger T.M., Behrens D.W., and Williams G.C., 1996. Coral Reef Animals of the Indo-Pacific. Sea Challengers publ., Monteray, California, 314pp.

7. Lăng Văn Kẻng, 1996. Sơ bộ nghiên cứu về thành phần loài và phân bố của thân mềm chân bụng (Gastropoda - Mollusca) của quần đảo Trường Sa. Tuyển tập nghiên cứu biển, tập VII. NXB Khoa học và Kỹ Thuật, Trang 94-102.

8. Nguyễn Văn Long (chủ nhiệm đề tài) 2006. Điều tra, nghiên cứu rạn san hô và các hệ sinh liên quan vùng biển từ hòn Chảo đến Nam đèo Hải Vân và bán đảo Sơn Trà. Báo cáo tổng kết đề tài, Viện Hải dương học, 142 trang.

9. Nguyễn Văn Long, Hoàng Xuân Bền, Phan Kim Hoàng và Hứa Thái Tuyến, 2009. Kết quả giám sát rạn san hô định kỳ tại Ninh Thuận 2007 - 2008. Báo cáo kỹ thuật, Viện Hải Dương Học, 11 trang.

10. Nguyễn Văn Long, Hoàng Xuân Bền, Phan Kim Hoàng, Nguyễn An Khang, Nguyễn Xuân Hoà và Hứa Thái Tuyến, 2006. Đa dạng sinh học và nguồn lợi sinh vật rạn san hô vùng biển Phú Quốc. Báo cáo kỹ thuật, Viện Hải dương học, 98 trang.

11. Nguyễn Văn Long, Hoàng Xuân Bền, Hứa Thái Tuyến, Phan Kim Hoàng, Nguyễn Xuân Hoà, 2007. Đa dạng sinh học của khu Bảo tồn biển vịnh Nha Trang, đánh giá lại 2002 - 2007. Báo cáo kỹ thuật, Viện Hải dương học, 74 trang.

12. Nguyễn Văn Long, Võ Sĩ Tuấn, Hoàng Xuân Bền, Phan Kim Hoàng, Hứa Thái Tuyến, Nguyễn Xuân Vỵ và Dương Trọng Kiểm, 2008. Đa dạng sinh học và chất lượng môi trường khu Bảo tồn biển Cù Lao Chàm 2004 - 2008. Báo cáo kỹ thuật, Viện Hải dương học, 110 trang.

13. Ninnette Lasola \& Hoang Xuan Ben, 2008. Assessment of Commercially important macro-invertbrates in the Spratly Group of Islands. Proceedings of the Conference on the Results of the Philippines-Vietnam Joint Oceanographic and Marine Scientific Research Expedition in the South China Sea (JOMSRE-SCS I to IV), 26 - 29 March 2008, Ha Long City, Vietnam, 285-292. 
PHỤ LỤC

DANH SÁCH THÀNH PHẦN LOÀI ĐỘNG VẬT KHÔNG XỦƠNG SỐNG KÍCH THƯỚC LỚN Ở VÙNG BIỂN VEN BỜ PHÚ YÊN

\begin{tabular}{|c|c|c|c|c|c|c|c|c|c|c|c|c|c|c|}
\hline \multirow[t]{2}{*}{ STT } & \multirow[t]{2}{*}{ Nhóm } & \multirow[t]{2}{*}{ Ho } & \multirow[t]{2}{*}{ Loài } & \multicolumn{11}{|c|}{ Vị trí khảo sát } \\
\hline & & & & 1 & 2 & 3 & 4 & 5 & 6 & 7 & 8 & 9 & 10 & 11 \\
\hline 1. & Sao biển & Ophidiasteridae & Linckia laevigata & + & + & + & + & + & + & + & + & + & + & + \\
\hline 2. & Sao biển & Ophidiasteridae & Nardoa $s p$ & + & + & & & & & & & & & \\
\hline 3. & Sao biền & Ophidiasteridae & Fromia sp & & & & & & & + & & & + & \\
\hline 4. & Sao biển & Acanthasteridae & Acanthaster planci & + & + & + & + & + & & + & + & + & + & + \\
\hline 5. & Sao biển & Oreasteridae & $\begin{array}{c}\text { Culcita } \\
\text { novaeguineae }\end{array}$ & + & + & + & + & + & + & + & + & + & + & + \\
\hline 6. & Sao biển & Echinasteridae & Echinaster luzonicus & & + & + & & + & & + & + & & & + \\
\hline 7. & Hải sâm & Holothuridae & Holothuria atra & + & & + & & & & + & & + & & \\
\hline 8. & Hải sâm & Holothuridae & Holothuria edulis & + & + & + & & & & + & + & + & & \\
\hline 9. & Hải sâm & Holothuridae & $\begin{array}{l}\text { Holothuria } \\
\text { leucospilota }\end{array}$ & + & & & & & & & & & & \\
\hline 10. & Hải sâm & Holothuridae & Bohadschia argus & & & & & & & & & + & & \\
\hline 11. & Hải sâm & Holothuridae & Bohadschia graeffei & & & & & & & & & & & + \\
\hline 12. & Hải sâm & Synaptidae & Synapta maculata & + & + & + & & & & & + & + & + & + \\
\hline 13. & Hải sâm & Phyllophoridae & $\begin{array}{l}\text { Neothyonidum } \\
\text { magnum }\end{array}$ & + & + & & + & & & & + & + & & + \\
\hline 14. & Hải sâm & Stichopodidae & $\begin{array}{l}\text { Stichopus } \\
\text { chloronotus }\end{array}$ & + & & & & & & & & + & & \\
\hline 15. & Cầu gai & Diadematidae & Diadema setosum & + & + & + & + & + & + & + & & & & + \\
\hline 16. & Cầu gai & Diadematidae & Diadema savignyi & + & + & + & + & + & & + & & & & + \\
\hline 17. & Cầu gai & Diadematidae & $\begin{array}{l}\text { Echinothrix } \\
\text { calamaris }\end{array}$ & + & + & + & + & + & + & + & + & + & + & + \\
\hline 18. & Càu gai & Toxopneustidae & Tripneustes gratilla & + & + & + & + & + & + & + & + & + & + & + \\
\hline 19. & Cầu gai & Toxopneustidae & $\begin{array}{c}\text { Toxopneustes } \\
\text { pileolus }\end{array}$ & + & & & & + & & + & & & & + \\
\hline 20 & Cầu gai & Echinometridae & Echinometra sp & & & & & + & & & & & & \\
\hline 21 & Cầu gai & Echinometridae & Echinostrephus sp & & & & & & & & & + & & \\
\hline 22. & Cầu gai & Cidaridae & Prionocidaris sp & & & & & & & & & & + & \\
\hline
\end{tabular}




\begin{tabular}{|c|c|c|c|c|c|c|c|c|c|c|c|c|c|c|}
\hline \multirow[t]{2}{*}{ STT } & \multirow[t]{2}{*}{ Nhóm } & \multirow[t]{2}{*}{ Họ } & \multirow[t]{2}{*}{ Loài } & \multicolumn{11}{|c|}{ Vị trí khảo sát } \\
\hline & & & & 1 & 2 & 3 & 4 & 5 & 6 & 7 & 8 & 9 & 10 & 11 \\
\hline 23. & Thân mềm & Aglajidae & Chielidonura sp. & & & + & & & & & & & & \\
\hline 24. & Thân mềm & Arcidae & Anadara antiquata & + & & & & & & & & & & \\
\hline 25. & Thân mềm & Arcidae & Barbatia foliata & & & + & & & & + & + & & + & + \\
\hline 26. & Thân mềm & Bursidae & Bursa rhodostoma & & & & & + & & & & & & \\
\hline 27. & Thân mềm & Bursidae & Bursa granularis & + & & + & & & & + & & & & \\
\hline 28. & Thân mềm & Bursidae & Bursa lamarkii & & & & + & + & & & & & & \\
\hline 29. & Thân mềm & Bursidae & Tutufa oyamai & & & & & & & + & & & & \\
\hline 30. & Thân mềm & Carditidae & Fragum rugosum & & & & & + & & & & & & \\
\hline 31. & Thân mềm & Cerithiidae & Cerithium citrinum & & & & & & & & + & & & \\
\hline 32. & Thân mềm & Chromodoridae & $\begin{array}{c}\text { Chromodoris } \\
\text { bullockii }\end{array}$ & & & + & & & & & & & & \\
\hline 33. & Thân mềm & Chromodoridae & Chromodoris odhneri & & + & & & & & & & & & \\
\hline 34. & Thân mềm & Chromodoridae & $\begin{array}{c}\text { Chromodoris } \\
\text { tinctoria }\end{array}$ & & & + & & & & & & & & \\
\hline 35. & Thân mềm & Chromodoridae & Glossodoris cincta & & & & + & & & & & + & + & \\
\hline 36. & Thân mềm & Conidae & Conus flavidus & & & & & & & & + & & & \\
\hline 37. & Thân mềm & Conidae & Conus ebraeus & & & & + & & & & & + & & \\
\hline 38. & Thân mềm & Conidae & Conus lividus & + & & & + & + & & + & + & + & + & \\
\hline 39. & Thân mềm & Conidae & Conus miles & & & + & & + & + & & & & & \\
\hline 40. & Thân mềm & Conidae & Conus musicus & & + & + & + & + & & & + & + & & \\
\hline 41. & Thân mềm & Conidae & Conus rattus & & & & + & & & & & & & \\
\hline 42. & Thân mềm & Conidae & Conus sp. & & & & & + & & & & & & \\
\hline 43. & Thân mềm & Cymatidae & Cymatium pileare & & & & + & + & & & & & & \\
\hline 44. & Thân mềm & Cypraeidae & Cypraea arabica & + & & & & + & & & & + & + & \\
\hline 45. & Thân mềm & Cypraeidae & Cypraea talpa & + & & & & + & & & & & & \\
\hline 46. & Thân mềm & Fasciolariidae & Latirus polygonus & + & & & & + & & & & & & \\
\hline 47. & Thân mềm & Fasciolariidae & $\begin{array}{l}\text { Leucozonia } \\
\text { smaragdula }\end{array}$ & & & & & & + & & & & & \\
\hline 48. & Thân mềm & Fasciolariidae & Peristernia incarnata & + & & & & & & & + & & + & + \\
\hline 49. & Thân mềm & Haliotidae & Haliotis ovina & & & & & & & & & + & & \\
\hline 50. & Thân mềm & Malleidae & Malleus albus & & & & & + & & & & & & \\
\hline 51. & Thân mềm & Mitridae & Nebularia aurantia & & + & + & & & & & & & + & \\
\hline
\end{tabular}




\begin{tabular}{|c|c|c|c|c|c|c|c|c|c|c|c|c|c|c|}
\hline \multirow[t]{2}{*}{ STT } & \multirow[t]{2}{*}{ Nhóm } & \multirow[t]{2}{*}{ Ho } & \multirow[t]{2}{*}{ Loài } & \multicolumn{11}{|c|}{ Vị trí khảo sát } \\
\hline & & & & 1 & 2 & 3 & 4 & 5 & 6 & 7 & 8 & 9 & 10 & 11 \\
\hline 52. & Thân mềm & Mitridae & Strigatella decurtata & & & & + & + & & & & & & \\
\hline 53. & Thân mềm & Muricidae & Chicoreus brunneus & & & & & & & + & & & & \\
\hline 54. & Thân mềm & Muricidae & $\begin{array}{l}\text { Chicoreus } \\
\text { torrefactus }\end{array}$ & + & + & & + & + & + & + & + & + & + & + \\
\hline 55. & Thân mềm & Muricidae & $\begin{array}{c}\text { Coraliophilla } \\
\text { neritoidea }\end{array}$ & + & + & + & + & + & + & + & & & + & + \\
\hline 56. & Thân mềm & Muricidae & Drupa ricina & & & & + & + & + & + & + & + & & \\
\hline 57. & Thân mềm & Muricidae & Drupa rubusidaeus & & & & & & & + & & & & \\
\hline 58. & Thân mềm & Muricidae & Drupella cornus & + & + & + & + & & + & + & + & + & & + \\
\hline 59. & Thân mềm & Muricidae & $\begin{array}{l}\text { Habromorula } \\
\text { spinosa }\end{array}$ & & & & + & & & + & & & & \\
\hline 60. & Thân mềm & Muricidae & $\begin{array}{l}\text { Homalocantha } \\
\text { anatomica }\end{array}$ & & & + & + & & & & & & & \\
\hline 61. & Thân mềm & Muricidae & $\begin{array}{l}\text { Mancinella } \\
\text { mancinella }\end{array}$ & & & & + & + & & & + & & & \\
\hline 62. & Thân mềm & Muricidae & Marchia triptera & & & & & & & + & & & & \\
\hline 63. & Thân mềm & Muricidae & Pascula muricata & & & + & & & & & & & & \\
\hline 64. & Thân mềm & Ovulidae & $\begin{array}{l}\text { Calpurnus } \\
\text { verrucosus }\end{array}$ & + & + & & & & & & + & + & + & \\
\hline 65. & Thân mềm & Ovulidae & Ovula ovum & & & & + & & + & & + & + & & \\
\hline 66. & Thân mềm & Pectinidae & $\begin{array}{c}\text { Pedum } \\
\text { spondyloideum }\end{array}$ & + & + & + & & & & + & & & + & + \\
\hline 67. & Thân mềm & Personidae & Distorsio anus & & & & & & & & & + & + & \\
\hline 68. & Thân mềm & Phyllidiidae & Phyllidia varicosa & & & & + & & + & + & & + & & \\
\hline 69. & Thân mềm & Phyllidiidae & Phyllidia coelectis & + & & & + & & & & & & & \\
\hline 70. & Thân mềm & Phyllidiidae & Phyllidia geometrica & & & & & + & & & & & & \\
\hline 71. & Thân mềm & Phyllidiidae & Phyllidia striata & & + & & + & & & & & & + & \\
\hline 72. & Thân mềm & Phyllidiidae & $\begin{array}{c}\text { Phyllidiella } \\
\text { pustulosa }\end{array}$ & + & & + & + & & + & + & + & & + & \\
\hline 73. & Thân mềm & Phyllidiidae & Phyllidiella sp. & & + & & & & + & & & & & \\
\hline 74. & Thân mềm & Pinnidae & Atrina vexillum & + & + & + & & + & & + & & & + & + \\
\hline 75. & Thân mềm & Pinnidae & Pinna sp. & & & & & & & + & & & & \\
\hline 76. & Thân mềm & Pteriidae & Avicula sp. & & + & & & & & & & & & \\
\hline
\end{tabular}




\begin{tabular}{|c|c|c|c|c|c|c|c|c|c|c|c|c|c|c|}
\hline \multirow[t]{2}{*}{ STT } & \multirow[t]{2}{*}{ Nhóm } & \multirow[t]{2}{*}{ Họ } & \multirow[t]{2}{*}{ Loài } & \multicolumn{11}{|c|}{ Vị trí khảo sát } \\
\hline & & & & 1 & 2 & 3 & 4 & 5 & 6 & 7 & 8 & 9 & 10 & 11 \\
\hline 77. & Thân mềm & Pteriidae & $\begin{array}{c}\text { Pinctada } \\
\text { margaritifera }\end{array}$ & & & + & & & & + & + & & & + \\
\hline 78. & Thân mềm & Pteriidae & Pteria sp. & & & & & & & & & & & + \\
\hline 79. & Thân mềm & Spondylidae & Spondylus ducalis & & & + & & + & & + & & & + & + \\
\hline 80. & Thân mềm & Spondylidae & Spondylus sp. & & & & & & + & & & & & \\
\hline 81. & Thân mềm & Strombidae & Lambis crocata & & & & & + & & & & & & \\
\hline 82. & Thân mềm & Strombidae & Lambis lambis & + & & & & & & + & + & + & + & \\
\hline 83. & Thân mềm & Strombidae & Lambis scorpius & & + & & + & & & + & & + & & + \\
\hline 84. & Thân mềm & Strombidae & Strombus luhuanus & & & & & + & & & & & & \\
\hline 85. & Thân mềm & Strombidae & Strombus sp. & & & & & + & & & & & & \\
\hline 86. & Thân mềm & Strombidae & $\begin{array}{c}\text { Strombus } \\
\text { aurisdianae }\end{array}$ & & & & & & & & & & + & \\
\hline 87. & Thân mềm & Tridacnidae & Tridacna crocea & + & + & & + & & & + & & + & + & + \\
\hline 88. & Thân mềm & Tridacnidae & Tridacna maxima & & & & + & + & & + & + & + & & \\
\hline 89. & Thân mềm & Tridacnidae & Tridacna squamosa & + & + & & + & & & & + & & + & \\
\hline 90. & Thân mềm & Trochidae & Tectus pyramis & + & + & & + & + & + & + & + & + & + & + \\
\hline 91. & Thân mềm & Trochidae & Trochus conus & & & & & + & & & + & + & + & + \\
\hline 92. & Thân mềm & Trochidae & Trochus maculatus & & + & + & + & & + & + & + & & + & \\
\hline 93. & Thân mềm & Turbinellidae & Vasum turbinellus & & & + & + & + & + & + & & & & \\
\hline 94. & Thân mềm & Turbinidae & Angaria delphinus & & & & + & + & & + & & + & & \\
\hline 95. & Thân mềm & Turbinidae & $\begin{array}{l}\text { Astralium } \\
\text { rhodostoma }\end{array}$ & & & & + & + & & & + & + & + & + \\
\hline 96. & Thân mềm & Turbinidae & Turbo bruneus & + & & & + & & & & & & + & \\
\hline 97. & Thân mềm & Turbinidae & Turbo chrysostomus & & & & + & + & + & + & + & + & & \\
\hline & & Tổng & & 35 & 29 & 30 & 39 & 40 & 20 & 40 & 31 & 34 & 32 & 27 \\
\hline
\end{tabular}

Ghi chú: 1- bãi Nồm; 2- vịnh Hoà; 3- Tù̀ Nham; 4- vũng La; 5- hòn Yến; 6- bãi Phú; 7bãi Nam; 8- hòn Chùa; 9- hòn Dúa; 10- bãi Gò; 11- hòn Nưa 


\title{
ASSESSMENT OF MACRO-INVERTEBRATES ON CORAL REEFS IN THE COASTAL WATERS OF PHU YEN PROVINCE
}

\author{
HOANG XUAN BEN, HUA THAI TUYEN
}

\begin{abstract}
The result is determined 97 taxa belonging to the 40 families. The Mollusc is greatest with 75 species and 16 families, Echinoderm and Holothurian contribute eight species and four families, eight species and three families respectively. The species composition of species at the depth transect line is higher than that at the shallow transect line. The species composition at some sites is high at Hon Yen and Bai Nam (40 species), Bai Nom (35 species) and Hon Dua (34 species). The diverse index is the highest at Hon Yen, Bai Go and the lowest at Vung La, Bai Phu. The average density of macro-invertebrates is valued 20.9 individual per $100 \mathrm{~m}^{2}$, the average density is the highest at Hon Nua with 42 individual per $100 \mathrm{~m}^{2}$ and the lowest at Bai Phu with 4.5 individual per $100 \mathrm{~m}^{2}$. It is shown at all of the sites that the average density of macro-invertebrates at the depth transect is higher than that at the shallow transect with 25.4 individual per $100 \mathrm{~m}^{2}$ and 15.2 individual per $100 \mathrm{~m}^{2}$ respectively. The density of macro-invertebrates is focused on the Echinoderm group which 19.1 individual per $100 \mathrm{~m}^{2}$ (the ratio of $91.1 \%$ ). The results are shown that the community of macro-invertebrates belongs to three structural groups in the coastal waters of Phu Yen province. The community A is recorded at Vung La, Bai Phu, and Hon Chua. The community $B$ is determined at Bai Nom, Vinh Hoa, Bai Nam, Bai Go, and Hon Nua. The community C is defined at Hon Yen and Tu Nham.
\end{abstract}

Ngày nhận bài: 18 - 01 - 2010

Ngườ nhận xét: ThS. Bùi Quang Nghị 